\title{
Examining Potential Residential Participation in Financial Incentives to Mitigate Impervious Surface Effects in Howard County, Maryland
}

\author{
Kristin M. Larson \\ Johns Hopkins University, klarson8@alumni.jh.edu \\ Jim Caldwell \\ Howard County Office of the Executive, jcaldwell@howardcountymd.gov \\ Alexander Cloninger \\ University of Maryland, alex@math.umd.edu
}

Follow this and additional works at: https://digitalcommons.usf.edu/subsust

Part of the Environmental Policy Commons, Sustainability Commons, and the Water Resource Management Commons

\author{
Recommended Citation \\ Larson, Kristin M.; Caldwell, Jim; and Cloninger, Alexander (2014) "Examining Potential Residential \\ Participation in Financial Incentives to Mitigate Impervious Surface Effects in Howard County, Maryland," \\ Suburban Sustainability. Vol. 2 : Iss. 1 , Article 2. \\ http://dx.doi.org/10.5038/2164-0866.2.1.2 \\ Available at: https://digitalcommons.usf.edu/subsust/vol2/iss1/2
}

This Article is brought to you for free and open access by the Open Access Journals at Digital Commons @ University of South Florida. It has been accepted for inclusion in Suburban Sustainability by an authorized editor of Digital Commons @ University of South Florida. For more information, please contact digitalcommons@usf.edu. 


\section{Examining Potential Residential Participation in Financial Incentives to Mitigate Impervious Surface Effects in Howard County, Maryland}

\section{Cover Page Footnote}

Acknowledgements - Thank you to Elissa Reineck for her help distributing the electronic survey to residents on the Live Green Howard County e-mail list, and thank you to Daniel Somers, Jennifer Guillaume, and Bob Spencer for providing BMP participation numbers for their respective programs. 


\section{Introduction}

Impervious surfaces now enclose urban life. Roofs, roads, driveways, and sidewalks all tend to be comprised of materials that cannot be penetrated by water such as metal, concrete, brick, or asphalt. This impermeability of urban surfaces has been found to degrade water sources through excess stormwater volumes and the accumulation of pollutants, making the existence of impervious surfaces a significant environmental concern. Urban stormwater runoff can degrade streams by altering volume, pattern, and quality of flow, and most water quality problems in urban landscapes result from water retention loss in soil (Booth and Leavitt 1999; Walsh et al 2012). Precipitation falls onto impervious surfaces and does not filter into the ground where pollutants can degrade. Instead, precipitation rapidly runs off those surfaces and is channeled into storm drains, all the while collecting more pollutants, and ultimately, the now highly concentrated precipitation is transferred back into surface and ground waters (Booth 1991; Gobel et al 2007).

Numerous studies provide evidence of a link between urban runoff and negative environmental impacts and reveal how the presence of impervious surfaces are strong environmental indicators of water resource degradation (Arnold and Gibbons 1996). For example, correlations have been found between high amounts of impervious surface and low fish health and between the presence of asphalt driveways and harmful pollutants (Wang et al 2003; Gilbert and Clausen 2006). Nationwide, the U.S. Environmental Protection Agency (EPA) found that urban runoff is the second most important cause of lakes and estuaries deterioration (U.S. EPA 1994). This is largely due to the introduction of excess nitrogen and phosphorus from plant and lawn fertilizers, pet waste, etc., which contribute to the harmful eutrophication of water. Eutrophication impairs water for both humans and wildlife, creating algal blooms that cause loss of oxygen in water and by releasing harmful toxins (Carpenter et al 1998). Such knowledge has stemmed the creation of urban stormwater federal, state, and local regulation.

At a federal level, there have been a number of notable efforts within the Clean Water Act to reduce water pollution from stormwater, although none specific to the regulation of impervious surfaces. In 1987, a major stormwater reduction effort was the addition of Municipal Separate Storm Sewer System's (MS4s) regulation in the Clean Water Act. Polluted urban runoff is commonly transported through MS4s and then discharged untreated into local waterbodies. Another more recent stormwater reduction effort was the creation of the Chesapeake Bay Total Maximum Daily Load (TMDL) in 2010, which involves reductions of both point sources and nonpoint sources. Despite extensive restoration efforts for 25 years, the Chesapeake has continued to have low water quality. This TMDL is the largest developed by the EPA. It sets limits for nitrogen, phosphorus, and sediment in the District of Columbia, Maryland, New York, Pennsylvania, Virginia, West Virginia, and Delaware. Plans to comply with the Chesapeake Bay TMDL heavily involve urban stormwater management (U.S. EPA 2010). 
Legislation efforts regarding both stormwater and impervious surface reduction are also present at the state and county level. On the forefront is Maryland. In response to the EPA's Chesapeake TMDL, Maryland passed House Bill 987, which requires ten of its counties to adopt and implement local laws or ordinances necessary to establish an annual stormwater remediation fee and a local watershed protection and restoration fund to provide finance for the implementation of local stormwater management plans. It also requires that the remediation fee be based on the share of stormwater management services related to an individual property, which may be a flat or graduated rate based on the amount of impervious surfaces on a property, or another method (Maryland HB. No. 987 2012).

The focus area chosen for this study is Maryland's Howard County, one of the ten counties exploring how best to enact their own stormwater fee based on the amount of impervious surface on a property. Due to the fact that most of Howard County's land is privately owned, and that it has increasing impervious surface, it is critical to have residential properties involved in remediation (Howard County 2012; Sexton et al 2013). The County decided funds generated at least in part would provide financial incentives that would encourage residential participation in efforts to reduce impervious surface effects on one's property. If a successful incentive program was developed, this would help the county in efforts to comply with stormwater goals outlined by the State of Maryland and Chesapeake TMDL requirements immensely.

County financial incentives to be provided were for the Best Management Practices (BMPs) of rain gardens, cisterns, and permeable pavers installations. Rain gardens are defined as low located areas filled with native plants that will reduce rainwater runoff, increase groundwater recharge, and provide pollutant treatment, all through the uptake and filtering of rainwater (Prince George's County 2007; Dietz 2007). Cisterns are large above or below ground tanks for storing water, in which the water stored can be filtered for home use and can reduce large volumes of runoff by collecting water from house roofs (Grady and Younos 2008). Permeable pavers are substitutes to impervious pavement and are made out of materials that will allow water to filter though. Permeable pavers have been shown to reduce stormwater runoff and increase water quality (Brattebo and Booth 2003). While other source control practices were considered, Howard County's expected focus was on promoting the aforementioned solutions on individual properties.

These BMP incentives, if offered, would have an insignificant impact on reduction targets without high residential participation. More information is needed to understand which BMP financial incentives would provide the highest residential participation, and how best to structure incentives to attain high participation. This information will be beneficial not only for Howard County but also for other Maryland counties, and for other governments that will pursue residential impervious surface reductions in the future. Individual stormwater fees are on the rise due to advances in remote sensing that allow for readily available individual parcel level data (Keeley 2007). 
It is estimated that the number of stormwater utilities in the United States will increase dramatically from two in 1974 to 2,500 in the next decade (Woolson 2004; Keeley,2007). Most current literature available focuses on the negative effects of stormwater runoff and the potential of impervious surface alternatives and BMPs to reduce runoff. Few have focused on public perception or willingness to participate in alternatives (Fletcher et al 2011; Thurston et al 2010). This study's aim is to elucidate any barriers that prevent Howard County residents from installing rain gardens, cisterns, or permeable pavers as well as to estimate the potential participation in those BMPs if a financial incentive program is provided.

\section{Methods}

Howard County has an area of about 251 square miles and is situated between Baltimore, Maryland and the District of Columbia. It is an affluent community of 111, 612 households and nearly $75 \%$ of the population are homeowners (U.S. Census Bureau 2010). Initial qualitative data from stormwater program managers in Maryland and DC were collected to gain information about their experiences with financial incentive programs for BMPs. This information was used to develop a nine question survey to distribute to Howard County homeowners in February 2013 prior to impervious surface fee implementation (Appendix 1). The first six questions of the survey were descriptive questions about the homeowner. The questions asked about income, length of homeownership, gender, age, and familiarity with impervious surface environmental issues, and familiarity with the new planned impervious surface fee in Howard County. The next questions each related to the homeowner's familiarity with the three different BMPs that were the county's focus, and their willingness to complete that practice.

Surveys were distributed to Howard County residents in person and electronically. During in person intercept surveys, questions written on paper were shown and read to participants in the same way and recorded in person by the same surveyor at central public areas in three different neighborhoods of Howard County. Those neighborhoods were Columbia, North Laurel, and West Friendship. The neighborhoods were chosen as survey sites because they had differed geographic locations and income demographics based on current census data. North Laurel is located in south Howard County. Columbia is located in north Howard County, and West Friendship is located in west Howard County. Most neighborhood demographics were similar in average age and family size, but household income varied in neighborhoods in the county. Columbia has a median household income of $\$ 101,267$. North Laurel has a median household income of $\$ 84,617$. West Friendship has a median income level of $\$ 138,169$ (U.S. Census Bureau 2010).

Distributing surveys in these chosen three neighborhoods allowed for the ability to analyze if neighborhoods in Howard County had significantly different 
responses. In each neighborhood, 20-25 surveys were collected in person depending on foot traffic (21 in Columbia, 25 in North Laurel, 20 in West Friendship). All survey participants were screened initially to see if they were homeowners that were currently living in Howard County. Those that responded they were not a homeowner in Howard County were not asked to participate in the survey. Electronic versions of the survey with questions posed in the exact way as in person surveys were distributed to an e-mail list of those that provided their information to Live Green Howard County or that applied for a Howard County free tree program. Electronic surveys were utilized in order to reach this subset of Howard County's population. These additional surveys were collected in order to analyze if there was a difference between the random population and those that were already somewhat environmentally involved. The electronic survey was stated for Howard County homeowners in the February 2013 Live Green newsletter. The newsletter was sent to 2,569 residents inboxes, but information about the survey was only viewed by 64 residents ( $2.5 \%$ of total emails sent), and then completed by 44 residents $(\sim 69 \%$ of those that viewed the survey). In addition to distributed surveys, participation numbers in similar BMP incentive programs were collected from RainScapes in Montgomery County, Maryland, RiverSmart Homes in the District of Columbia, and RainWise in Seattle, Washington. These values were used for further comparison and as a supplement to survey results to determine expected participation in BMPs.

Distributed surveys were first analyzed by tabulating the frequency of responses for each survey question. Then surveys were analyzed using Pearson chisquared tests to determine if there were significant differences in responses between different neighborhoods and between random sample and Live Green responses. Lastly, both Pearson chi-squared tests and probit regressions were used to analyze statistical difference between each independent variable (questions 1-6) and each dependent variable (questions 7-9) as well as other trends between one response and another. All Pearson chi-squared tests and probit regressions were calculated in MATLAB 2009. For the probit regressions, the questions for payback time and willingness to pay were averaged (normalized to scale) as these questions reflect similar sentiment for willingness to participate in the program. The Cronbach's alpha scores for this factor were 0.7403 for rain gardens, 0.7015 for cisterns, and 0.7290 for permeable pavers, implying the factor is correct. Also, the explanatory variables of length of homeownership and age were combined into a factor by averaging their normalized values, as there is exceedingly high correlation between these questions. The Cronbach's alpha score for this factor was 0.7117 (Cronbach 1951). Furthermore, homeowner participation data from already existing BMP inventive programs were tabulated to compare to all survey results. 


\section{Results}

In total, there were 110 surveys analyzed $(n=110)$. Clear patterns and trends in survey results were indicated and were found to be well supported by collected participation data from existing residential financial incentive BMP programs. F-statistics for the rain garden, cistern, and permeable pavers probit regressions imply the fit of each of the regressions is significant as compared to a null model. Among all three regressions, the maximum correlation between any two factors was 0.3408 , which is well within reason.

\section{Descriptive Factors}

In regards to the first six questions of the survey, which were descriptive questions about the homeowner, the largest percentage of survey respondents have been a homeowner more than 10 years $(97 \%)$, have an annual household income over $\$ 130,000(45 \%)$, are female (56\%), and are 46-55 (37\%) in age. Most respondents had a household income of $\$ 80,000$ or more $(84 \%)$. Also, more survey respondents specified themselves as somewhat familiar with impervious surface environmental issues, $(82 \%)$, but then most had not heard about the new impervious surface based fee proposed for Howard County (72\%). Influential descriptive factors in determining a respondent's willingness to participate in BMPs were evaluated. The strongest statistical differences found were between age and both willingness to pay and payback time willingness with those older than 55 willing to pay less and wait less for payback of installing rain gardens, cisterns, and permeable pavers (Table 1). Further significant findings were found between higher income and willingness to pay more for permeable pavers, and between those with increased knowledge about the proposed impervious surface fee and higher willingness to pay more for rain gardens and permeable pavers (Tables 2 - 4). Also, a marginally significant difference was found between those with knowledge of impervious surface environmental issues and their willingness to pay more for all three BMPs. No statistical difference was found between gender and responses. 
Table 1. Pearscon Chi-Squared Test Results

\begin{tabular}{|c|c|c|c|}
\hline Group Analyzed & BMPs & Responses & $\chi^{2}$ Statistic \\
\hline \multirow{6}{*}{$\begin{array}{l}\text { Live Green } \\
\text { Member }\end{array}$} & \multirow[t]{2}{*}{ Rain Garden } & Willingness to Pay & $10.4821^{*}$ \\
\hline & & Payback Time Willingness & $13.2833^{* *}$ \\
\hline & \multirow[t]{2}{*}{ Cistern } & Willingness to Pay & $10.9436^{*}$ \\
\hline & & Payback Time Willingness & $8.381^{* *}$ \\
\hline & \multirow[t]{2}{*}{ Permeable Pavement } & Willingness to Pay & $16.4563^{* *}$ \\
\hline & & Payback Time Willingness & $7.2978^{*}$ \\
\hline \multirow{6}{*}{ Over Age 55} & \multirow[t]{2}{*}{ Rain Garden } & Willingness to Pay & $25.6163^{* *}$ \\
\hline & & Payback Time Willingness & $13.8713^{* *}$ \\
\hline & \multirow[t]{2}{*}{ Cistern } & Willingness to Pay & $30.6317 * *$ \\
\hline & & Payback Time Willingness & $29.1177 * *$ \\
\hline & \multirow[t]{2}{*}{ Permeable Pavement } & Willingness to Pay & $39.7608 * *$ \\
\hline & & Payback Time Willingness & $32.5344^{* *}$ \\
\hline \multirow{6}{*}{$\begin{array}{l}\text { Familiar with } \\
\text { Impervious } \\
\text { Surface Fee }\end{array}$} & \multirow[t]{2}{*}{ Rain Garden } & Willingness to Pay & 5.9487 \\
\hline & & Payback Time Willingness & 2.3883 \\
\hline & \multirow[t]{2}{*}{ Cistern } & Willingness to Pay & 7.1508 \\
\hline & & Payback Time Willingness & 7.7884* \\
\hline & \multirow[t]{2}{*}{ Permeable Pavement } & Willingness to Pay & $14.7767 * *$ \\
\hline & & Payback Time Willingness & $7.0683 *$ \\
\hline \multirow{6}{*}{$\begin{array}{l}\text { Aesthetics as } \\
\text { Top Concern }\end{array}$} & \multirow[t]{2}{*}{ Rain Garden } & ess to Pay & $10.1976^{*}$ \\
\hline & & Payback Time Willingness & 0.5856 \\
\hline & \multirow[t]{2}{*}{ Cistern } & Willingness to Pay & 3.2331 \\
\hline & & Payback Time Willingness & 2.1145 \\
\hline & \multirow[t]{2}{*}{ Permeable Pavement } & Willingness to Pay & $11.4567^{* *}$ \\
\hline & & Payback Time Willingness & $7.2447 *$ \\
\hline
\end{tabular}

Willingness to Pay has d.f. $=5$, Payback Time Willingness has d.f. $=3$

${ }^{*} p<.1,{ }^{* *} p<.05$ 
Table 2. Probit Regression on Willingness to Pay for Permeable Pavers ( $n=110$ )

\begin{tabular}{c|cc}
\hline Variable & Coefficient & t-Statistic \\
\hline Age/Home Tenure & -0.1141 & $-2.0248^{* *}$ \\
Income & 0.1522 & $2.2474^{* *}$ \\
Gender & 0.1061 & 1.0671 \\
Im. Surface Conscious & 0.1274 & $1.7262^{*}$ \\
Surface Fee Familiarity & 0.1543 & $2.3217^{* *}$ \\
HOA/COA & 0.0786 & 0.5472 \\
Lot Feasibility & -0.2753 & -0.8887 \\
Time Concern & 0.4840 & $2.0823^{* *}$ \\
Aesthetics & 0.4582 & $2.2111^{* *}$ \\
Maintenance & 0.0345 & 0.3072 \\
Initial Cost & 0.0854 & 0.8217 \\
Environmental Impact & 0.3126 & $2.8385^{* *}$ \\
$R^{2}=0.3709$, F-statistic $=4.1279$, p-value for F-statistic $=0.00003$ \\
\multicolumn{2}{|c}{$p<.1, * * p<.05$}
\end{tabular}

Table 3. Probit Regression on Willingness to Pay for Cistern (n=110)

\begin{tabular}{c|cc}
\hline Variable & Coefficient & t-Statistic \\
\hline Age/Home Teunure & -0.1264 & $-2.067^{* *}$ \\
Income & 0.0408 & 0.6139 \\
Gender & 0.0205 & 0.2197 \\
Im. Surface Conscious & 0.1436 & $1.7643^{*}$ \\
Surface Fee Familiarity & 0.0123 & 0.1801 \\
HOA/COA & -0.3261 & $-1.7353^{*}$ \\
Well Water & -0.2688 & -0.8875 \\
Lot Feasibility & -0.0302 & -0.1702 \\
Time Concern & -0.2786 & -0.9062 \\
Aesthetics & -0.1336 & -1.2039 \\
Maintenance & -0.0356 & -0.3291 \\
Initial Cost & -0.2904 & $-2.8392^{* *}$ \\
Environmental Impact & 0.2026 & $1.9284 *$ \\
\hline \multicolumn{2}{|c}{$* p<.1, * *$} & $p<.05$
\end{tabular}

Table 4. Probit Regression on Wilingness to Pay for Rain Garden (n=110)

\begin{tabular}{c|cc}
\hline Variable & Coefficient & t-Statistic \\
\hline Age/Home Tenure & -0.0990 & $-2.2504^{* *}$ \\
Income & 0.0778 & 1.4397 \\
Gender & 0.0852 & 1.1037 \\
Im. Surface Conscious & 0.1259 & $1.9141^{*}$ \\
Surface Fee Familiarity & 0.1111 & $2.0724^{* *}$ \\
HOA/COA & -0.0030 & -0.0250 \\
Lot Feasibility & 0.0372 & 0.2569 \\
Time Concern & -0.0645 & -0.3037 \\
Aesthetics & 0.1083 & 1.2122 \\
Maintenance & 0.0222 & 0.2647 \\
Initial Cost & 0.0689 & 0.8329 \\
Environmental Impact & 0.2604 & $3.0632^{* *}$ \\
$R^{2}=0.3247$, F-statistic $=3.3293$, p-value for F-statistic $=0.0004$ \\
\multicolumn{2}{c}{$* p<.1, * * p<.05$}
\end{tabular}




\section{Installing a Rain Garden, Cistern, or Permeable Pavers}

Respondents were most familiar with cisterns and rain gardens (63\% and $72 \%$ respectively), and less so with permeable pavers (47\%). Most respondents were willing to wait only zero to three years to see the payback on their investment for all practices (Fig. 1).

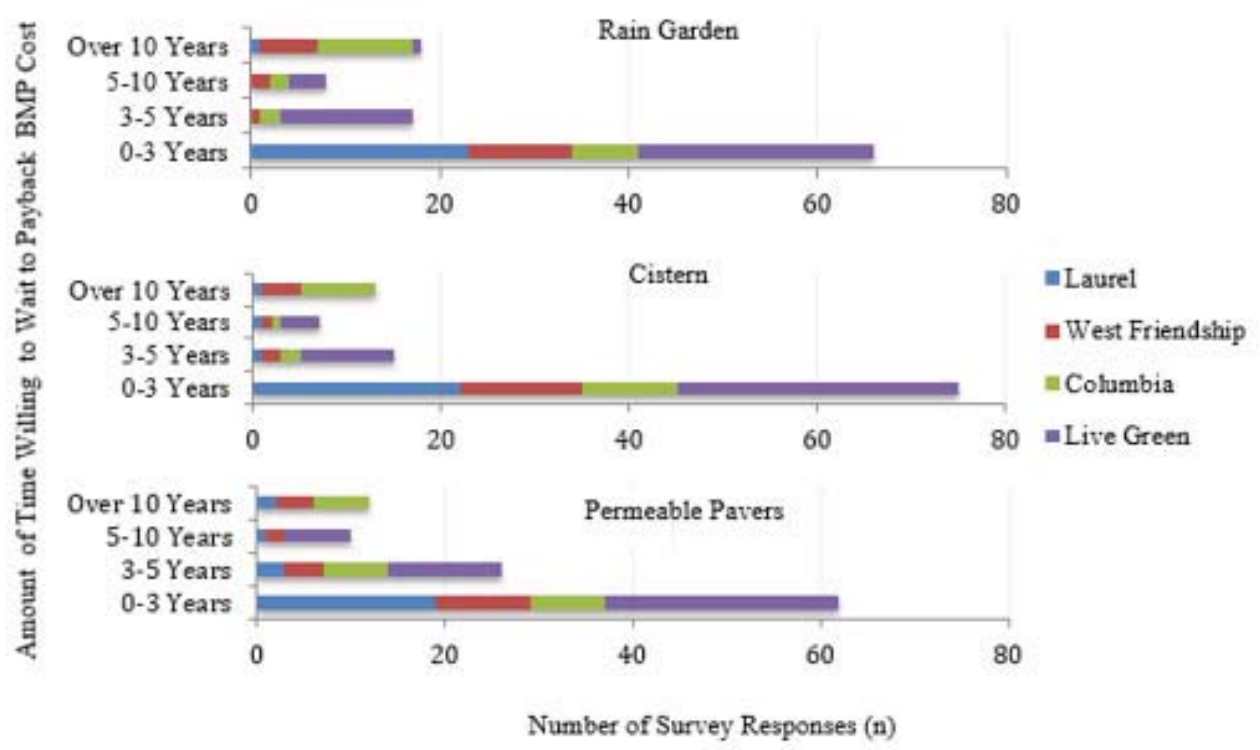

Figure 1. Payback Time Willingness to Complete a BMP Practice

The largest percentage of survey respondents were willing to pay $\$ 101-\$ 500(40 \%)$ to install a rain garden at their home, but not even willing to consider installing a cistern (34\%) or permeable pavers (26\%) (Fig. 2). However, willingness to pay for permeable pavers was the most varied and had the highest percentage of homeowners willing to pay higher amounts of money with $23 \%$ of respondents willing to pay $\$ 101-\$ 500,22 \%$ of respondents willing to pay $\$ 501-\$ 1000$, and $18 \%$ willing to pay $\$ 0-\$ 100$. Additionally, the majority of survey respondents said they would install all three BMPs if they received a large discount if five of more of their neighbors installed one (rain garden $74 \%$, cistern $61 \%$, permeable pavers $67 \%$ ). They also answered yes they would install one if they knew it cleaned local water as in this would be a factor in their decision (rain garden $72 \%$, cistern $69 \%$, permeable paver $71 \%$ ). 


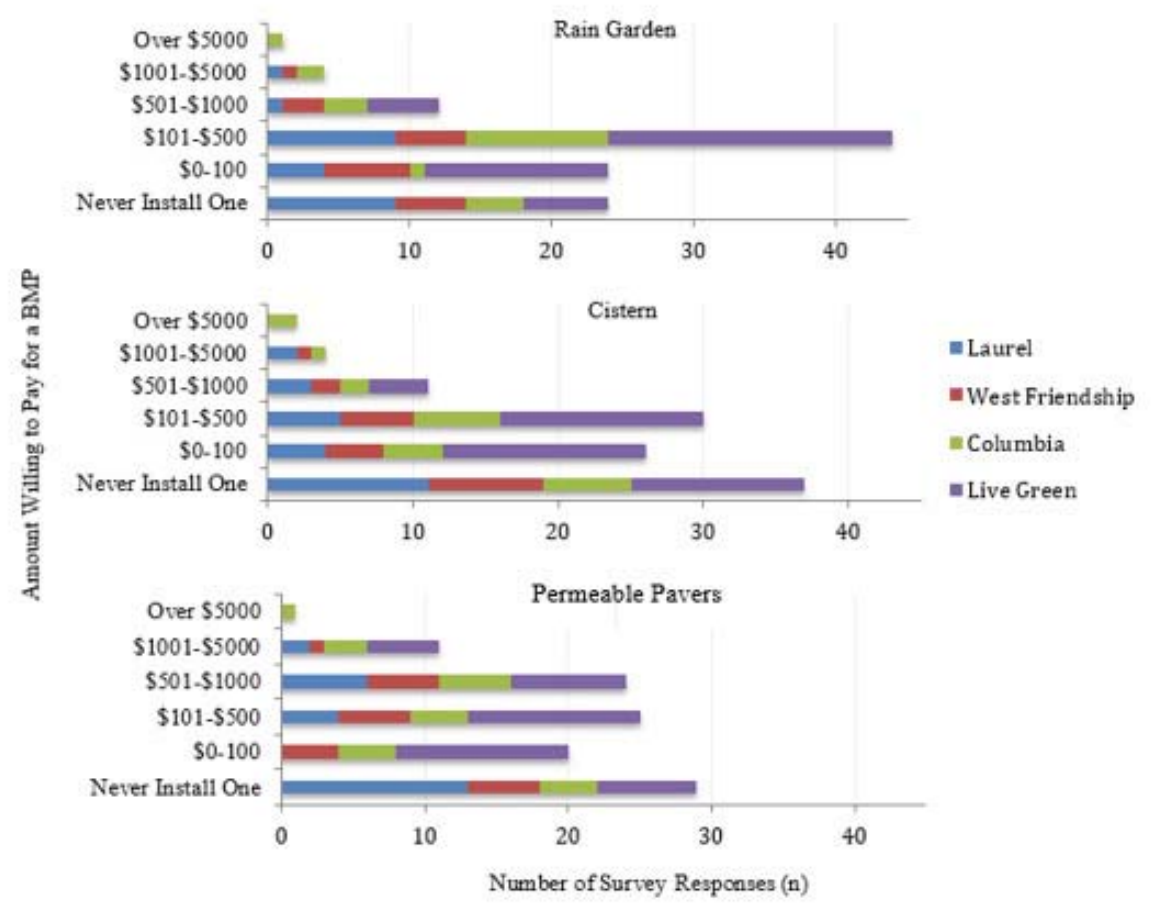

Figure 2. Willingness to Pay to Complete a BMP Practice

\section{Top Considerations}

The top three ranked considerations on whether or not to install a BMP were examined for each participant. The initial cost of the project was mentioned most frequently as a consideration. Survey responses were extremely varied for each BMP, but other heavily repeated answers include the maintenance, aesthetics, and environmental impact of the practice. Other notable considerations mentioned included: more information was needed, the homeowner's lot was not feasible, homeowner/condo association (HOA/COA) or common ownership community (COC) rules would not allow installation, a homeowner's advanced age, and the time involved to complete the project (Fig. 3). Top considerations that yielded significant or marginally significant differences in regards to willingness to pay were aesthetics, initial cost, $\mathrm{COC}$, time concern, and environmental impact. 


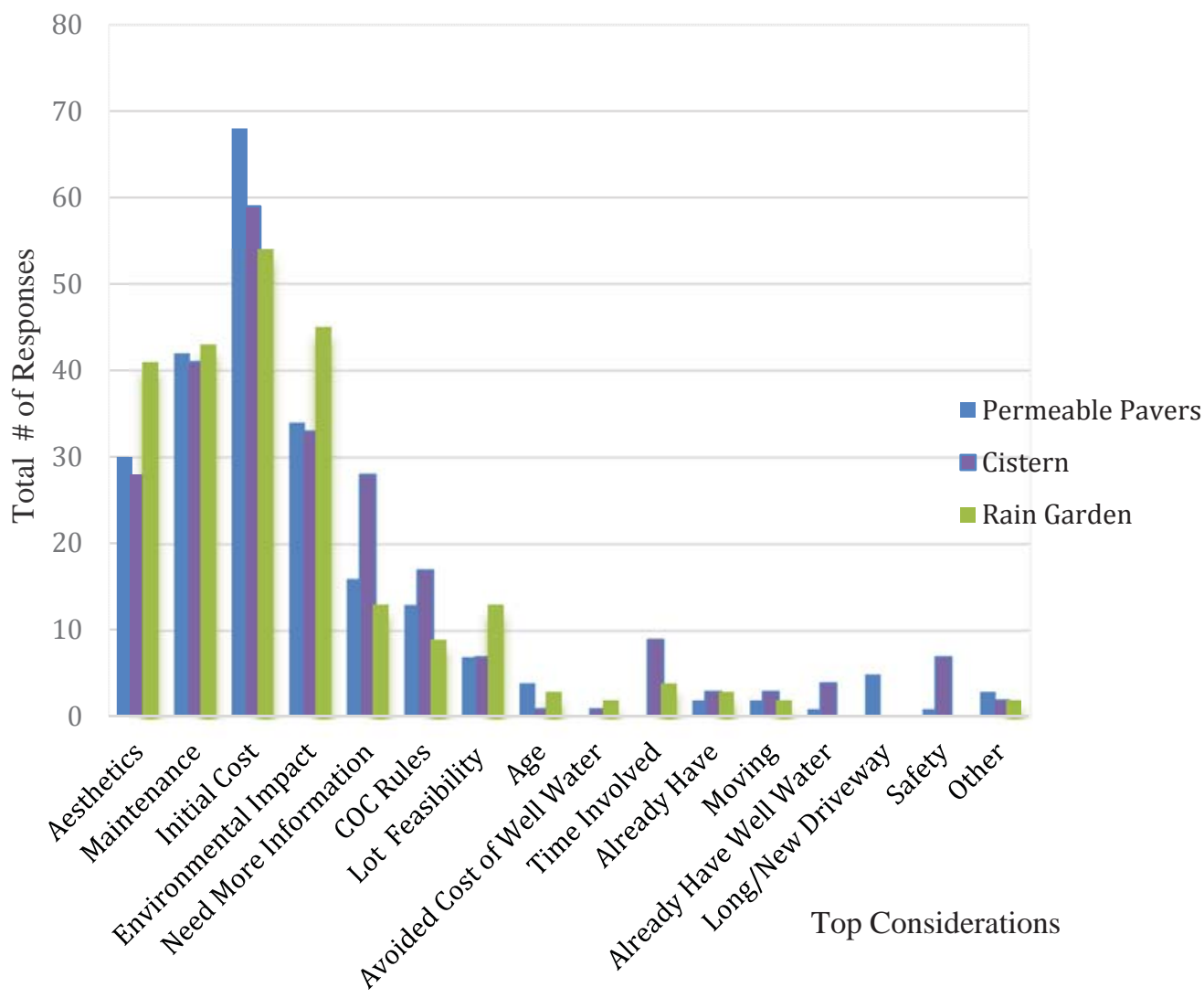

Figure 3. Top Considerations for Installing Permeable Pavers, Cistern, or Rain Garden

\section{Neighborhood and Live Green Responses}

Survey results were analyzed for significant differences between responses from those in different neighborhoods (North Laurel, Columbia, and West Friendship) and those that were already environmentally involved in Howard County's Live Green newsletter. There was no significant difference found between neighborhood responses to any questions that were asked. However, there was a marginally significant or significant difference found in responses between the Live Green survey takers and the other survey respondents in regards to their willingness to pay more and willingness to wait longer for a return on their investment for all three BMPs. 


\section{Existing Residential Incentive Programs}

For comparison with analysis completed, participation numbers from existing residential BMP incentive programs were collected (Fig. 4).

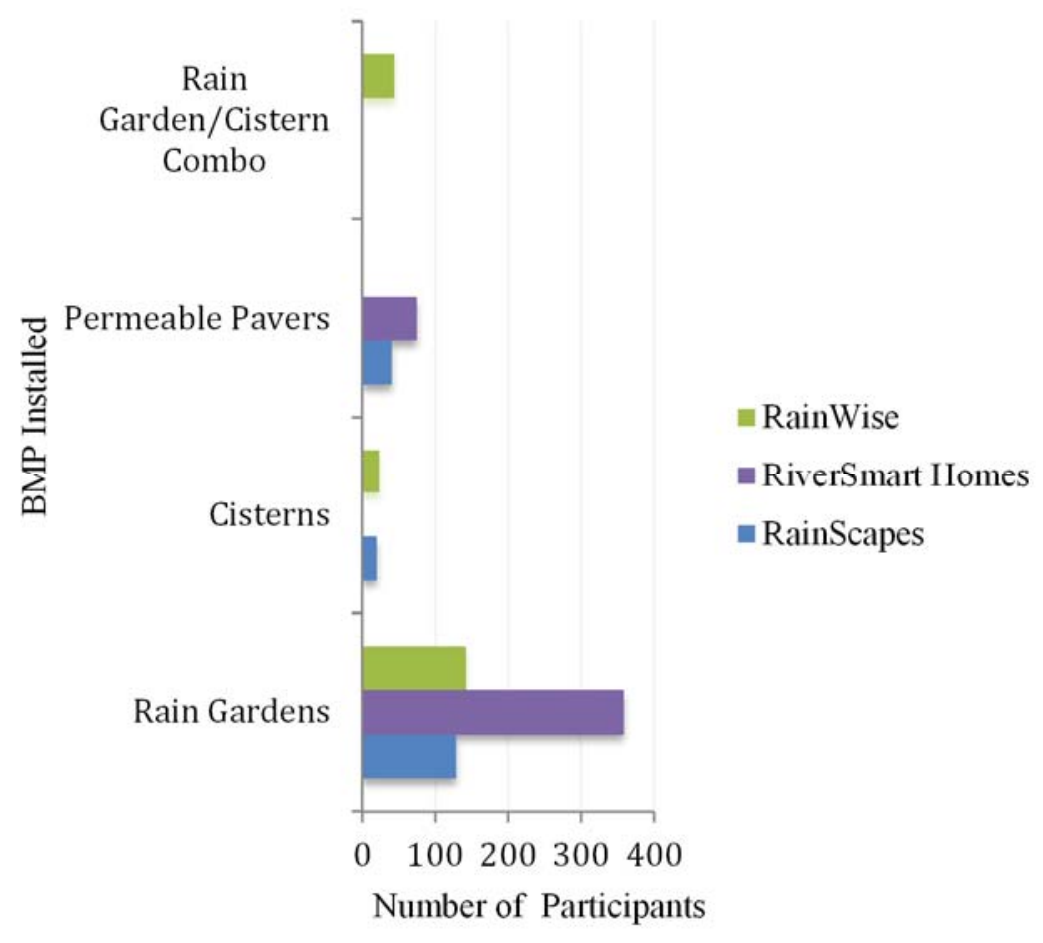

Figure 4. Participation Numbers in Existing BMP Financial Incentive Programs

The RainScapes program of Montgomery County had 129 rain gardens, 20 cisterns, and 41 permeable pavers installed from 2008- 2013. ${ }^{1}$ The rain garden rebate was based on square footage ( $\$ 5-\$ 9$ per foot squared based on media depth) or $\$ 1200$ per rain garden, whichever is greater. Their permeable pavers rebate was $\$ 4$ per square foot or $\$ 1200$, whichever is greater (100 square foot minimum), and had a cistern rebate for $\$ 1$ per gallon (250 gallons-500 gallons). The RiverSmart Homes program in the District of Columbia had 359 rain gardens, 75 permeable pavers, and zero cisterns installed from 2009-2012. ${ }^{2}$ Rain garden and permeable pavers rebates were for $\$ 1.25$ per impervious square foot treated. The minimum square footage treated was 400 square feet, which would provide a $\$ 500$ rebate. The maximum rebate was $\$ 1,000$ for treating 800 square

${ }^{1}$ D. Somers, personal communication, Feb. 2, 2013

2 J. Guillaume, personal communication, Jan. 31, 2013 
feet or more of impervious surface. The RiverSmart Homes program has an incentive for rain barrels and cisterns, but it is principally marketed for rain barrels. They did not had anyone participate in the cistern rebate as of mid-April 2013. Homeowners could purchase up to two cisterns, install it, and then receive $\$ 50$ to $\$ 500$ back with the rebate at $\$ 1$ per gallon stored. The RainWise program from 2010-2012 had 142 rain gardens, 23 cisterns, and 44 combo rain garden and cisterns installed. ${ }^{3}$ If a home was located in a targeted combined sewer outflow area, the RainWise program in most cases covered $100 \%$ of the cost of installing rain gardens and cisterns based on $\$ 3.50$ per square foot of roof area where the runoff is being directed into a rain garden. The average rebate paid was $\$ 4,400$.

\section{Discussion}

It is interesting that regardless of the incentive structure in other government programs, participation in the three BMPs had very similar participation levels. Thus, participation from Howard County homeowners in the three studied BMPs can be expected to be low in comparison to the total number of residential households in the County and have similar participation numbers to incentive programs investigated. Also, it is expected that there will be the most residential participation in a rain garden financial incentive compared to participation numbers from similar incentive programs and this study's findings of homeowners' higher willingness to pay for this BMP. Participation in permeable pavers are expected to be less than rain gardens, and participation in the cistern incentive are expected to be the least of the three, again based on participation numbers from similar incentive programs and willingness to pay findings.

\section{Homeowner Participation Barriers}

It is apparent financial incentives alone do not insure high participation in BMPs. The three mitigation practices individually each may cost $\$ 500$ (small cistern) to thousands of dollars (large cistern, rain garden, permeable pavers) depending on the size of the practice executed, but few homeowners valued practices at $\$ 501$ or more and were not willing to invest in an practice that did not pay for itself in zero to three years. This was despite the fact that the largest percentage of participants' household income were over $\$ 130,000$ annually and most homeowners' household incomes were over $\$ 80,000$ annually. However, most homeowners would not even consider installing cisterns or permeable pavers even if the practice had no initial cost associated with it. This is further evident in the similar low participation levels in BMPs in Seattle's RainWise Program when in most cases $100 \%$ of the cost of rain gardens and cisterns are rebated to homeowners.

\footnotetext{
${ }^{3}$ B. Spencer, personal communication, Feb. 5, 2013
} 
Therefore, it is important to examine other underlying barriers that create a low value to be placed on these practices, and the opportunity to increase participation may be influenced by incentive structure or perhaps other efforts such as community based education or social marketing (Costanzo et al 1986; Giacalone et al 2010; Mckenzie-Mohr 2000). Age was found to be the most significant barrier. Studies have continuously found a correlation between age and lower value placed on environmental services. Mohai and Twight (1987) indicated age as "the strongest and most consistent predictor of environmental concern." Pate and Loomis (1997) found those that were older would be less willing to pay for programs to reduce environmental issues in San Joaquin Valley in California. Moreover, Nixon and Saphores (2007) found older adults were less likely to indicate support for advanced recycling programs, and numerous more studies have yielded similar results.

High-perceived maintenance of all three BMPs was another significant barrier to implementation revealed. Maintenance was a heavily selected consideration in a homeowner's decision to participate in a BMP. Although, there was a mix of perceptions of whether each action was high or low maintenance. Homeowners expressed concern for practices that they perceived to be high maintenance and praised practices that they perceived as low maintenance vocally and in written responses on electronic surveys. Rain gardens, cisterns, and permeable pavers are all considered low maintenance actions, but still require some upkeep, which seemed to discourage homeowners. Homeowners also mentioned concern with the time involved in the initial process of installing the BMP. Maintenance and time barriers are very concerning, because low knowledge about maintenance and little willingness to commit time results in not only low participation but signals failure in years to come. Woodward et al (2008) found a similar lack of maintenance education in the implementation of a rain garden program in North Carolina, and two years after installation the majority of rain gardens installed were either in need of maintenance or abandoned.

Aesthetics, another exposed barrier, also had a mix of perceptions for each BMP. Rain gardens have aesthetically favorable aspects, and were the most popular BMP financial incentive of the programs that were examined in this study. Cisterns, without aesthetically favorable aspects, had the lowest participation numbers of the mitigation programs examined. The program manager of RainWise in Seattle noted similar aesthetic findings within the program and suggests cistern participation numbers were lower because they do not have the aesthetics of rain gardens. ${ }^{4}$ Hardstanding permeable pavers have been found to be aesthetically pleasing to homeowners (Wright et al 2011). However, homeowners were the least familiar with permeable pavers, and therefore, may not yet have a strong opinion of its aesthetics, which could explain this practices' lower participation numbers, and the varied willingness to pay for it.

\footnotetext{
${ }^{4}$ B. Spencer, personal communication, Feb. 5, 2013
} 
Lot feasibility issues encompassed a wide variety of other barriers for homeowners. Lack of lot space, buildup of water, and existing open spaces on properties are a few mentioned in this study. For example, homeowners that responded that they have large open spaces were mainly surveyed from the West Friendship neighborhood of Howard County and perceived that BMPs would only provide negligible stormwater benefit. In the case of installing permeable pavers, homeowners did not want to participate if they had a newly installed or long driveway, with those homeowners not wanting to pay the cost of installing the pavers. In the case of installing cisterns, there were questions of the safety of collected water quality, and one person mentioned a risk of child drownings in large underground tanks. In the West Friendship neighborhood, cisterns also stirred the discussion of well water. Some homeowners wanted to install a cistern to save on well water, while others would not install a cistern because they already had well water and perceived that there will be no additional benefit available for them. One respondent even specified that they already have well water as a top consideration in their decision on whether or not to install permeable pavers, as in the context of they are already doing their part in impervious surface mitigation.

However, the biggest lot feasibility issue was installing BMPs on a property within a homeowner or condo association. Those who are in a COC must gain approval from their committee before completing any of the BMPs included in this study. It is estimated there are 1,045,000 homeowners that live in 5,226 COCs in the state of Maryland (Fishbein 2012). This equates to about 18\% of Marylanders (U.S. Census Bureau 2010). Community associations were found to be a substantial barrier, with homeowners doubtful that they would be able to get approval from their association or unwilling to put in the effort to get that approval. This will not occur only in Maryland. Nationwide, there are 286,000 community associations with 23.1 million housing units, and that number is growing. In 1970, there were only 10,000 communities (Community Association Institute 2013).

It is important to note, all evaluated underlying barriers contain misconceptions about the three BMPs to some extent, and allude to yet another barrier, which is the knowledge of the cost and benefits of the mitigation practice. Most respondents were not familiar with the planned impervious surface based fee prior to this survey and did not factor the added cost of an impervious surface fee in their responses. Also, though most respondents indicated that they were somewhat familiar with impervious surface issues, it was very apparent many different misconceptions about the practices still existed, and perceived knowledge was higher than actual knowledge of impervious surface issues. Moreover, needing information about practices was one of the top five most frequent responses in a homeowner's decision to complete a practice. 


\section{Homeowner Participation Catalysts}

There is not one solution or catalyst that will remove all of the underlying barriers that exist for homeowners when deciding to participate in a BMP. Homeowners have a variety of different values and priorities, which is evident in the barriers outlined. However, there are methods or several small catalysts combined that can lessen barriers and help increase the value of these three BMPs, and thus provide the basis for higher participation in practices. These small catalysts include lowering the initial cost of a practice, providing more maintenance resources, highlighting aesthetic benefits, and providing effective education for homeowners about practices. Also, incentive efforts should focus efforts on young homeowners, COCs, and entire communities.

The initial cost was listed as the top consideration for each BMP, but the high initial cost barrier of the three practices would be alleviated by the proposed Howard County financial incentives. Howard County planned to offer $\$ 1200$ for the completion of a residential rain garden, $\$ 1200$ for the completion of permeable pavers over 100 square feet, and for a cistern that is at least 250 gallons, there is a maximum $\$ 500$ rebate that is based on a $\$ 1$ per gallon of water stored (Howard County Council 2013). These are very similar to Montgomery County and the District of Columbia financial incentives, and thus, would result in similar participation numbers. This will initiate participation, but as indicated it will not be sufficient to achieve high participation numbers in relation to the total number of residential properties in Howard County.

Maintenance resources could complement financial incentives to increase BMP participation. Homeowners were found not to be familiar with the maintenance required for practices. Resources could be providing periodic maintenance presentations, informative materials, or installing demonstration gardens as in the case of Woodward et al (2008). Maintenance resources could also include adjusting rebates within the financial incentive structure to include funding for maintenance tools or resources. For example, in the case of rain gardens that could include rebating annual mulch. In the case of cisterns, this could include rebating water-testing fees, and in the case of permeable pavers, this could include rebating annual regenerative sweeping of pavement. More studies are needed to determine the most effective approach for encouraging BMP maintenance.

Promoting aesthetics could also complement financial BMP incentives. It was found that aesthetically pleasing practices influence higher participation levels. Rain gardens have aesthetically pleasing components and in each financial incentive program examined, rain gardens by far were the most popular choice out of the three practices studied. While highlighting the aesthetic benefits of a cistern would be challenging, there is opportunity to increase homeowner participation in permeable pavers by highlighting and promoting their aesthetics. Homeowners that selected aesthetics as a top

consideration in their decision on whether or not to install permeable pavers were found to be willing to pay more to install them. If homeowners find the aesthetics of permeable pavers pleasing it could increase participation in the practice. 
Yet another complement to financial incentives that would increase participation is education about BMPs. This study found that $69-71 \%$ of respondents noted that if they knew each BMP cleaned local water, they stated yes they would install the practice. Additionally, Live Green participants were found to be willing to pay more for a practice and wait longer for the payback of that practice. Those that indicated they had at least some knowledge of impervious surface issues and those that responded environmental impact as a top consideration in their decision to install a practice were also willing to pay more. Education adds value to the installation of BMP actions. Those that are already knowledgeable or show interest in BMP practices seem to be more likely to participate in more than one practice. RainWise had larger cistern participation numbers when they combined the installation of a rain garden with a cistern.

Education about practices would also increase participation by dissolving misconceptions about them. Homeowner's with yards that have water issues would be more aware that rain gardens, cisterns, and permeable pavers could potentially reduce water buildup on their property. For homes that have larger lots and well water, such as in the West Friendship neighborhood, it should be apparent that impervious surfaces from roofs and driveways are still impacting stormwater systems and local waterways.

Furthermore, it should be apparent to homeowners how to prevent safety issues associated with cisterns. For instance, as with any water source, regular water testing should be completed. Also, though they have occurred, child drownings are rare in high-income countries and can be easily avoided by installing heavy grills over rainwater collection sites (World Health Organization 2012).

Correspondingly, educational information needs to be provided in an effective and engaging way. For instance, Mckenzie-Mohr (2000) indicated that when promoting water conservation, the use of a community based marketing strategies (a visit from student employee, a water gauge, a prompt of when to water, and a signed commitment) decreased water use 39\% more than when just providing a homeowner with an informational packet. Such community strategies could be developed in the case of encouraging BMPs. One way to accomplish this is by targeting new homeowners when they first move into a house by having them sign a commitment. In addition, finding ways to strongly target COCs to participate in financial incentives could increase participation numbers. COC associations are based on protecting property values, and especially with rain gardens aesthetics, added property value could be a way to get more COC homeowners involved.

For those who are not in homeowner's association, devising a way to involve entire neighborhoods or communities could further still increase participation numbers. When asked if homeowners would install BMPs if they received a large discount if five or more of their neighbors installed one, more than $60 \%$ of homeowners responded yes they would for each practice. Green et al. (2012) found that social capital is vital to the acceptance of stormwater BMPs. Yoeli et al. (2013) found that publicly posting sheets that required residents to print their name and unit number when signing up for a peak 
energy use reduction program, were nearly three times more likely to participate in the program. Involving whole communities could be accomplished by allowing larger incentives in communities that have a certain number of households involved or by providing opportunities for homeowners to view not only their individual impervious surface environmental impact and stormwater reductions but that of their community in a public tracking system.

While these small catalysts have the potential to increase participation numbers, the size of the increase is unknown, and there is still the question of whether the fee and incentive instrument is the most effective way to accomplish stormwater reduction goals. Fee/incentive instruments or price instruments are legally acceptable and equitable based on the cost of the service provided as measured directly or by some approximation of use. However, they still have some faults, such as not accounting for connectivity of impervious surfaces and the resulting variation in observed runoff volumes (Parikh et al 2005). Thurston et al $(2003,2010)$ found that a market based tradable allowance mechanism or reverse auctions may be a cost-effective alternative to a price instrument. However, more research needs to be completed on the effectiveness of other mechanisms to determine if participation levels would increase more dramatically.

\section{Conclusion}

Overall, this study provides a better understanding of potential residential participation in BMP financial incentives as well as underlying barriers and the catalysts available to alleviate existing barriers. Financial incentives alone have a low potential to initiate a high level of participation from residents in BMP practices on their properties. Homeowners have complex priorities and values that affect their decisions to install BMPs. Age, maintenance, aesthetics, lot feasibility, and knowledge were all identified as barriers that prevent the installation of rain gardens, cisterns, and permeable pavers on residential properties. Removing those barriers would provide potential catalysts to increase residential participation in BMPs. Catalysts identified were maintenance resources, promoting aesthetics, increased education, and targeting COCs or targeting entire communities. This study and future studies on this topic will be beneficial as more cities, counties, states, and other entities will be encouraging participation in BMPs on residential properties in the near future. More research is needed in order for those new BMP programs to achieve maximum success. 


\section{References}

Arnold, C. L. and Gibbons, C. J. 1996. Impervious Surface Coverage- The Emergence of a Key Environmental Indicator. Journal of American Planning Association 62(2): 243-258.

Booth, D. B. 1991. Urbanization and the National Drainage System- Impacts, Solutions, and Prognoses. The Northwest Environmental Journal 7(1): 93-118.

Booth, D. B., and Leavitt, J. 1999. Field Evaluation of Permeable Pavement Systems for Improved Stormwater Management. Journal of the American Planning Association 65(3): 314-325.

Brattebo, B.O. and Booth, D. B. 2003. Long-term Stormwater Quantity and Quality Performance of Permeable Pavement Systems. Water Research 37(18): 43694376.

Community Association Institute. 2013. Community Association Facts and Market Data. http://www.caidc.org/Community-Association-Facts-\&-MarketData 4442 221.htm.

Costanzo, M. and Archer, D., Aronson, E., Pettigrew, T. 1986. Energy Conservation Behavior: The Difficult Path from Information to Action. American Psychologist 41(5): 521-528.

Carpenter, S. R. and Caraco, N. F., Correll, D.L., Howarth, R. W., Sharpley, A.N., Smith, V.H. 1998. Nonpoint Pollution of Surface Waters with Phosphorus and Nitrogen. Ecological Applications 8(3): 559-568.

Cronbach, L. J. 1951. Coefficient Alpha and the Internal Structure of Tests. Psychometrika 16 (3): 297-334.

Dietz, M. E. 2007. Low Impact Development Practices: A Review of Current Research and Recommendations for Future Directions. Water, Air, and Soil Pollution 186 (1-4): 351-363.

Fletcher, T.D. and Walsh, C.J., Bos, D., Nemes, V., RossRakesh, S., Prosser, T., Hatt, B., Birch, R. 2011. Restoration of Stormwater Retention Capacity at the AllotmentScale though a Novel Economic Instrument. Water Science and Technology 64(2): 494-502. 
Fishbein, R. H. 2012. MHA and CCOC: Promoting Good Governance in Montgomery County. http://www.marylandhomeownersassociation.info /Site/Articles_of_Interest.html.

Giacalone, K. and Mobley, C., Sawyer, C., Witte, J., Eidson, G. 2010. Survey Says: Implications of a Public Perception Survey on Stormwater Education Programming. Journal of Contemporary Water Research and Education 146(1): 92-102.

Gilbert, J.K. and Clausen, J.C. 2006. Stormwater Runoff Quality and Quantity from Asphalt, Paver, and Crushed Stone Driveways in Connecticut. Water Research 40 (4): 826-832.

Gobel, P. and Dierkes ,C., Coldewey, W. G. 2007. Stormwater Runoff Concentration Matrix for Urban Areas. Journal of Containment Hydrology 91(1-2): 26-42.

Grady, C. and Younos, T. 2008. Analysis of Water and Energy Conservation of Rainwater Capture System on a Single Family Home. Virginia Water Resources Research Center, Blacksburg, SR39-2008.

Green, O. O. and Shuster, W.D., Rhea, L.K., Garmestani, A. S., and Thurston, H.W. 2012. Identification and Induction of Human, Social, and Cultural Capitals through an Experimental Approach to Stormwater Management. Sustainability 4: 16691682.

Howard County Council, Resolution No. 21. 2013. http://cc.howardcountymd.gov /DisplayPrimary.aspx?id=6442461878.

Howard County. 2012. Maryland Phase II Watershed Implementation Plan for the Chesapeake Bay. Howard County, Maryland. http://www.mde.state.md.us /programs /Water/TMDL/TMDL Implementation/Documents /FINAL_ PhaseII_Report_Docs/Final_County_WIP_Narratives /Howard_WIPII_2012.pdf.

Keeley, M. 2007. Using Individual Parcel Assessments to Improve Stormwater Management. Journal of the American Planning Association 73(2): 149-160.

Maryland Stormwater Management-Watershed Protection and Restoration Program, HB. No. 987. 2012. http://mgaleg.maryland.gov/2012RS/fnotes/bil_0007/hb0987.pdf.

McKenzie-Mohr, D. 2000. Promoting Sustainable Behavior: An Introduction to Community-Based Social Marketing. Journal of Social Issues 56(3): 543-554. 
Mohai, P. and Twight, B. W. 1987. Age and Environmentalism: An Elaboration of the Buttel Model Using National Survey Evidence. Social Science Quarterly 68(4): 798-815.

Nixon, H. and Saphores, J.D. 2007. Financing Electronic Waste Recycling: Californian Households' Willingness to Pay Advanced Recycling Fees. Journal of Environmental Management 84(4): 547-559.

Parikh, P. and Taylor, M.A., Hoagland, N.T., Thurston, H W., Shuster, W. 2005. Application of Market Mechanisms and Incentives to Reduce Stormwater Runoff: An Integrated Hydrologic, Economic, and Legal Approach. Environmental Science and Policy 8(2): 133-144.

Pate, J. and Loomis, J. 1997. The Effect of Distance on Willingness to Pay Values: A Case Study of Wetlands and Salmon in California. Ecological Economics 20(3), 199-207.

Prince George's County, Department of Environmental Resources. 2007. Bioretention Manual. http://www.aacounty.org/DPW/Highways/Resources/Raingarden /RG_Bioretention_PG\%20CO.pdf.

Sexton, J. O. and Song, X., Huang, C., Chengquan, H., Channan, S., Baker, M., Townsend J. 2013. Urban Growth of the Washington, D.C.-Baltimore, MD Metropolitan Region from 1984 to 2010 by Annual, Landsat-based Estimates of Impervious Cover. Remote Sensing of Environment 129: 42-53.

Thurston, H. W. and Goddard, H., Szlag, D., Lemberg, B. 2003. Controlling Stormwater Runoff with Tradable Allowances for Impervious Surfaces. Journal of Water Resources Planning and Management 129 (5): 409-418.

Thurston, H. W. and Taylor, M.A., Shuster, W.D., Roy, A.H., Morrison, M.A. 2010. Using a Reverse Auction to Promote Household Level Stormwater Control. Environmental Science and Policy 13 (5): 405-414.

U.S. Census Bureau. 2010. State and County Quickfacts: Maryland, Columbia, North Laurel, West Friendship, MD. http://quickfacts.census.gov/qfd/index.html. 
U.S. Environmental Protection Agency, Water Protection Division. 2010. Chesapeake Bay Total Maximum Daily Load for Nitrogen, Phosphorus and Sediment. http://www.epa.gov/reg3wapd/pdf/pdf_chesbay/FinalBayTMDL/CBayFinalTMDL ExecSumSection1through3_final.pdf.

U.S. Environmental Protection Agency, Office of Water. 1994. The Quality of our Nations Water: 1992. EPA841-S-94-002, Washington, D.C. http://www.epa.gov/nscep/index.html.

Walsh, C.J. and Fletcher, T.D., Burns, M.J. (2012) Urban Stormwater Runoff: A New Class of Environmental Flow Problem. PLoS ONE, 7(9): e45814.

Wang, L. and Lyons, J., Kanehl, P. 2003. Impacts of Urban Land Cover on Trout Streams in Wisconsin and Minnesota. Transactions of the American Fisheries Society 132(5): 825-839.

World Health Organization. 2012. Drowning. http://www.who.int/mediacentre /factsheets/ fs347/en/.

Woodward, M and Hunt, W. F., Hartup, W. 2008. Lessons Learned: The North Carolina Backyard Rain Garden Program. Proceedings of the 2008 International Low Impact Development Conference Seattle, WA: ASCE.

Woolson, E. 2004. Stormwater Utilities: Where do They Stand Now? Stormwater Magazine 5(5):12-23.

Wright, G. B. and Arthur, S., Bowles, G., Bastien, N., Unwin, D. 2011. Urban Creep in Scotland: Stakeholder Perceptions, Quantification and Cost Implications of Permeable Solutions. Water and Environment Journal 25 (4): 513-521.

Yoeli, E. and Hoffman, M., Rand, D.G., Nowak, M.A. 2013. Powering Up with Indirect Reciprocity in a Large-scale Field Experiment. Proceedings of the National Academy of Sciences of the United States of America 110 (2): 10424-10429. 


\section{Appendix 1. Survey for Howard County Homeowners}

Question 1: How long have you been a homeowner?

0-1 year

1-3 years

3-5 years

5-10 years

Over 10 years

Question 2: What is your household income level?

$\$ 30,000$ or Below

$\$ 30,001-\$ 80,000$

$\$ 80,001-\$ 130,000$

Over $\$ 130,000$

Question 3: What is your gender?

Male or Female

Question 4: What is your age?

Age: $\quad 0-25 \quad 26-35 \quad 36-45 \quad 46-55 \quad 56-65 \quad 66-75 \quad$ Over 76

Question 5: Are you familiar with impervious surface (ground covered by material that water cannot filter through such as driveways, roads, roofs, etc.) environmental issues?

Very Somewhat Not at all

Question 6: Are you familiar with new proposed impervious surface fee for Howard County residents?

Yes Somewhat Not at all 
Question 7: Are you familiar with a Rain Garden?

Yes or No If no, ask survey attendant.

Would you install a Rain Garden for your home today if it saved you money within...

0-3 years? Yes or No

3-5 years? Yes or No

5-10 years? Yes or No

10 or more years? Yes or No

How much would you be willing to pay today to install a Rain Garden at your home?

I would never install one

$\$ 0-\$ 100$

$\$ 101-\$ 500$

$\$ 501-\$ 1000$

$\$ 1001-\$ 5000$

Over $\$ 5000$

Would you install a Rain Garden if you were able to get a large discount if 5 or more of your neighbors installed a Rain Garden?

Yes or No

Would you install a Rain Garden at your home if you knew it cleaned local water?

Yes or No 
Which considerations are most important in your decision to install a Rain Garden?

Rank your top considerations in order of importance:

_Aesthetics

_.Maintenance

_Initial Cost

_Environmental Impact

_.Need More Information

_Other: Explain:

Question 8: Are you familiar with a Cistern?

Yes or No If no, ask survey attendant.

Would you install a Cistern at your home today if it saved you money within....

\begin{tabular}{llll} 
0-3 years? Yes & or & \multicolumn{2}{c}{ No } \\
3-5 years? Yes & or & \multicolumn{2}{c}{ No } \\
5-10 years? Yes & or & \multicolumn{2}{c}{ No } \\
10 or more years? Yes & or No
\end{tabular}

How much would you be willing to pay today to install a Cistern at your home?

I would never install one

$\$ 0-\$ 100$

$\$ 101-\$ 500$

$\$ 501-\$ 1000$

$\$ 1001-\$ 5000$

Over $\$ 5000$

Would you install a Cistern at your home if you were able to get a large discount if 5 or more of your neighbors installed a Cistern?

Yes or No 
Would you install a Cistern at your home if you knew it cleaned local water?

Yes or No

Which considerations are most important in your decision to install a Cistern?

Rank your top considerations in order of importance:

_Aesthetics

_-Maintenance

_ Initial Cost

_.Need More Information

_Environmental Impact

_Other: Explain:

Question 9: Are you familiar with Permeable Pavers?

Yes or No If no, ask survey attendant.

Would you install Permeable Pavers at your home today if it saved you money within....

0-3 years? Yes or No

3-5 years? Yes or No

5-10 years? Yes or No

10 or more years?

How much would you be willing to pay today to install Permeable Pavers at your home?

I would never install it

$\$ 0-\$ 100$

$\$ 101-\$ 500$

$\$ 501-1000$

$\$ 1001-\$ 5000$

Over $\$ 5000$ 
Would you install Permeable Pavers at your home if you were able to get a large discount if 5 or more of your neighbors installed Permeable Pavers?

Yes or No

Would you install Permeable Pavers at your home if you knew it cleaned local water?

Yes or No

Which considerations are most important in your decision to install Permeable Pavers?

Rank your top considerations order of importance:

_Aesthetics

Maintenance

__nitial Cost

_Environmental Impact

_ Need More Information

Other: Explain: 